\title{
Reward preferences for generations in selected Information and Communication Technology companies
}

\author{
Authors: \\ Annetjie Moore \\ Mark Bussin ${ }^{1}$ \\ Affiliations: \\ ${ }^{1}$ Department of Industrial \\ Psychology and People \\ Management, University of \\ Johannesburg, South Africa \\ Correspondence to: \\ Mark Bussin \\ Email: \\ drbussin@mweb.co.za \\ Postal address: \\ PO Box 524, Auckland Park \\ 2006, South Africa \\ Dates: \\ Received: 20 Sept. 2010 \\ Accepted: 18 Apr. 2012 \\ Published: 25 Sept. 2012 \\ How to cite this article: \\ Moore, A., \& Bussin, \\ M. (2012). Reward \\ preferences for generations \\ in selected Information \\ and Communication \\ Technology companies. SA \\ Journal of Human Resource \\ Management/SA Tydskrif vir \\ Menslikehulpbronbestuur, \\ 10(1), Art. \#325, 9 pages. \\ http://dx.doi.org/10.4102/ \\ sajhrm.v10i1.325
}

C 2012. The Authors.

Licensee: AOSIS

OpenJournals. This work

is licensed under the

Creative Commons

Attribution License.
Orientation: Previous research suggests that different generations have different reward preferences based on differences in values, frames of reference and life goals.

Research purpose: The focus of this study was to determine whether different generations prefer different rewards in the Information and Communication Technology (ICT) industry in South Africa.

Motivation for the study: The rationale for this study was to obtain a better understanding of the reward preferences of Veterans, Baby Boomers, Generation X and Generation $\mathrm{Y}$ in the ICT industry.

Research design, approach and method: The research was a quantitative, cross-sectional, correlational design. Participants from two ICT companies completed a structured electronic survey. One hundred and sixty four valid responses were received. A Cronbach's alpha of 0.821 indicates that the survey was reliable.

Main findings: Contrary to previous research, the results show that generations do not display different reward preferences.

Practical/managerial implications: It would be more beneficial to use individual interrelationship factors to develop a reward strategy than generations.

Contribution/value-add: The research has added insight and value to reward preferences for generations in the ICT sector.

\section{Introduction}

\section{Problem statement}

The rationale of this study was to determine whether generations such as Veterans, Baby Boomers, Generation $X$ and Generation $Y$, prefer specific reward schemes, in line with their beliefs, values, needs, drivers and world views. Generations refer to categories of people, who are grouped together as a result of certain events, which had a major impact on their lives, such as World War 11 or 9/11 in New York or the first democratic election in South Africa in 1994. The aforementioned generations form the bulk of the South African and other world economies at the moment. Theory states that generations will differ in their reward preferences.

Recent research (Giancola, 2008), reports no correlation between reward preference and generations in the USA. However, Van Rooy (2010) found that in the South African financial sector different generations valued rewards differently. It would appear that an inconsistency exists between generation theory and research.

\section{Background to the study}

Giving employees choices regarding their remuneration packages has become a topical issue in South African organisations (Bussin, 2003). This is in terms of rewards to ensure performance, job satisfaction and retention of the best people with critical skills to make the company successful. Companies want high performing individuals and employees want to be rewarded in line with performance, value add and personal choices.

In an ever-changing, fast moving world, where the only real differentiator in business lies in people's competence, it is of the utmost importance to win the talent war to attract, develop, motivate and retain the best people in the industry (Chiang \& Birtch, 2005; Mohlala, 2011). One way of doing this is to design reward strategies to suit individual choice. This research was exploratory and the primary research objective was to determine whether there are any reward preferences amongst generations in the Information and Communication Technology (ICT) sector. 
Research by Chiang and Birtch (2005) suggests that reward systems in a high technology environment may be different to other sectors. Mohlala (2011) points out that the Information Technology (IT) skills talent pool is shrinking as a result of increasing demands for IT professionals, and rapidly developing technology across industries. This is especially true in a competitive environment where products are quickly copied, and a difficult business climate, fierce rivalry and globalisation prevail (Chiang \& Birtch, 2005).

\section{Trends from research literature}

The concept of personal differences and personal choice is not new in the remuneration and reward sphere. For example MacGrain Herkenhoff (2002) investigated the role of culture in reward preferences; and Nienaber and Bussin (2009) analysed reward preferences from a personality perspective.

\section{Research objectives}

There are conflicting views as to whether employees in the various generations would prefer different rewards. Articles and non-academic books generally go to great lengths explaining the differences between the generations and emphasising that they want different things. Very little empirical research has been carried out to show whether or not this is the case. The objective of this research was to determine whether generations within the ICT sector have different reward preferences. The results are intended to assist companies with their remuneration designs and offerings.

\section{Value add of this research}

This research has added insight and value to the area of reward preferences for generations in the ICT sector. It has become clear that money matters to all generations, as it was ranked either first or second by all four generations. Should this reward cocktail be mixed in line with the likes and dislikes of individuals, ICT companies may experience a higher retention rate of knowledge workers, which could result in better customer services and increased profits.

As mentioned above, the ICT sector faces challenges of scarce skills. Staff mobility between companies occurs when better career prospects and higher salaries are offered. Continuous up-skilling of staff and the provision of career trajectories are critical to retain staff members. Being able to match the reward structure to the preferences of staff is a key talent retention strategy (Mohlala, 2011). Staff turnover becomes a recurring, costly cycle and the root problem is often not determined. It is not unusual in organisations, according to a P-E Corporate Survey (September, 2010), to have an average annual staff turnover for $22 \%$ of ICT staff and $8.5 \%$ for general staff.

This research argues that a meaningful way to determine staff members' aspirations is to talk to the individuals' on a regular basis and to build solid and credible relationships.

The next sections set out a review of the literature, research design, findings and discussion including recommendations and implications of the study.

\section{Synthesis and critical evaluation of the literature Conceptual definitions of key concepts}

This research uses the definition of reward as including pay, benefits, learning and development and the work environment (Bussin, 2002a). Generations are defined as categories of people who are grouped in line with major events in their lifetime as per Table 1 for South Africa.

Table 1 indicates how generations are categorised by identifying different dates as periods. These periods are linked to key events, which had a major impact on the generations. These dates or periods are similar, but not exactly the same in all countries, as different events influenced different countries' generations (Codrington \& Grant-Marshall, 2004).

\section{Literature review Reward preference research}

MacGrain Herkenhoff (2000) argues that national cultural differences should be considered when improving the effectiveness of reward systems. Previous international studies have indicated that reward preferences are influenced by culture (MacGrain Herkenhoff, 2000) and demographic variables (Corporate Leadership Council, 2002). Further, significant gaps have been found between what employees report as their top reasons for joining and leaving organisations and what employers think these reasons are (Ellis, 2009). It is for this reason that research into the characteristics and preferences of employees is essential when developing a reward strategy.

Nienaber and Bussin (2009) found that total rewards models structured according to individual preferences, positively influence efforts to attract, retain and motivate key

TABLE 1: Generation timelines in different countries.

\begin{tabular}{|c|c|c|c|c|}
\hline Generation & USA & Europe or UK & Japan & South Africa \\
\hline Gl'sì & $1900-1923$ & $1900-1918$ & $1900-1925$ & 1900-1920 \\
\hline Veterans & 1924-1942 & 1919-1945 & 1926-1945 & $1921-1940$ \\
\hline Boomers & 1943-1962 & 1946-1965 & 1946-1965 & 1941-1960 \\
\hline Generation X & 1963-1983 & 1966-1984 & 1966-1985 & 1961-1980 \\
\hline Generation $Y$ & $1984-2007 \dagger$ & 1985-2007† & $1986-2007 \ddagger$ & 1981-2007٪ \\
\hline
\end{tabular}

Source: Codrington, G., \& Grant-Marshall, S. (2004). Mind the Gap! Johannesburg: Penguin Books (Pty) Ltd

$\dagger, \mathrm{Gl}$ is an acronym for 'Government Issue' and is commonly used to refer to veterans who fought in World War II.

$\$$, The boundaries for Generation $Y$ are still flexible. Different cut-off dates will gradually emerge for different countries or regions marking the end of Generation $Y$. 
employees. Yet, this is seldom carried out. Structuring total rewards models according to the preferences of employee segments is a viable alternative to accommodating individual preferences. Nienaber and Bussin's (2009) study focussed on the relationship between personality types, personality preferences, temperaments, demographic variables and reward preferences to enhance understanding of reward preferences for different segments. Their main findings indicated statistically significant differences in respect of the reward preferences of people in different segments and they concluded that management can more effectively structure reward models according to these preferences without increasing overall costs (Nienaber \& Bussin, 2009).

Typically, generic reward schemes are implemented in companies according to job grading systems to pay employees in the workplace (Bussin, 2002b). Reward preferences in line with specific generation requirements have not been widely considered. According to Karp, Fuller and Sirias (2002) policies are often created by Baby Boomers and the needs of Generation X and Generation Y are not always catered for. This in return generates a gap between the reward system and the expectations of employees.

The rationale behind the present study was to obtain a better understanding of the reward preferences of Veterans, Baby Boomers, Generation $X$ and Generation $\mathrm{Y}$ in the ICT sector. This is useful for the way rewards are structured and implemented. To date, research has mostly focused on remuneration and rewards per job categories and levels within the organisation and has not taken into account factors such as generation.

\section{Generations}

The generations identified for the twentieth century are the GI or Hero Generation, Veterans, Baby Boomers, Generation $X$ and Generation Y. Shelton and Shelton (2005), Lammiman and Syrett (2004) and Codrington and Grant-Marshall (2004), classified the differences amongst the generations. The generation gaps are resultant of cohorts or defining moments in people's lives and history. Some defining moments for each generation, are highlighted in Table 2.

This table illustrates the differences amongst the generations and how views and attitudes have changed between the Veterans and the Generation $Y$ in most aspects of life. Technology, for example, enabled the generations to communicate globally at the push of a button, whereas in the 1920s it took weeks to send a letter to another country.

If reward preference is based on some combination of values, motivations and preferences (Chiang \& Birtch, 2005), and generational theory states that generations differ in their attitudes, then it may be the case that generational differences will affect reward preferences.

\section{Reward systems}

People work to be rewarded and to obtain work satisfaction. Different people will require different 'formulas' in which they want to be rewarded for work completed. This research

TABLE 2: Differences in the generations.

\begin{tabular}{|c|c|c|c|c|}
\hline Attribute & Veterans (1920-1940) & Boomers (1941-1960) & Generation X (1961-1980) & Generation Y (1981-2007) \\
\hline $\begin{array}{l}\text { Defining values and } \\
\text { characteristics }\end{array}$ & Reserved, clean-living, gentlemanly & $\begin{array}{l}\text { Personal gratification, wellness, } \\
\text { success, bossy, stylish, inquisitive, } \\
\text { competitive, talkative }\end{array}$ & $\begin{array}{l}\text { Balance, self-reliance, } \\
\text { pragmatism, individualistic, } \\
\text { arrogant, risk-taking }\end{array}$ & $\begin{array}{l}\text { Respect, independent, loyal, } \\
\text { humour, tolerant, caring, honest, } \\
\text { balanced, optimistic, clean-cut }\end{array}$ \\
\hline Leadership & $\begin{array}{l}\text { Formal, hierarchical, loyal, hard- } \\
\text { working, low key, detail-orientated }\end{array}$ & $\begin{array}{l}\text { Visionary, idealistic, workaholic, } \\
\text { energetic, bossy, loud, } \\
\text { reward-driven, consensus }\end{array}$ & $\begin{array}{l}\text { Caution, creative, realistic, low key, } \\
\text { innovative, flexible, independent, } \\
\text { adaptable, competence }\end{array}$ & $\begin{array}{l}\text { Civil-minded, visionary, confident, } \\
\text { optimistic, moralistic, principled, } \\
\text { value-driven }\end{array}$ \\
\hline Communication & Burgeoning airmail, telephone & $\begin{array}{l}\text { Post, courier services, telex, } \\
\text { typewriters }\end{array}$ & $\begin{array}{l}\text { Personal computers, internet, } \\
\text { email, web, cellular phones }\end{array}$ & $\begin{array}{l}\text { Email, internet, web, sms, PC with } \\
\text { voice recognition, digital voice }\end{array}$ \\
\hline Likes & Security, stability & $\begin{array}{l}\text { Shopping, ostentation, winning, } \\
\text { leading, vision }\end{array}$ & $\begin{array}{l}\text { Sharing, chilling, being } \\
\text { individualistic, being with } \\
\text { friends, change }\end{array}$ & $\begin{array}{l}\text { Shopping, labels, family, friends, } \\
\text { the environment, technology }\end{array}$ \\
\hline Dislikes & $\begin{array}{l}\text { Debt, borrowing, upstart young } \\
\text { people }\end{array}$ & Paying off debt, aging & Bossiness, corporate culture & $\begin{array}{l}\text { Dishonesty, unbalanced life, } \\
\text { ostentation }\end{array}$ \\
\hline Defining events & $\begin{array}{l}\text { Discover penicillin, Great } \\
\text { Depression, World War II, } \\
\text { Pearl Harbour, Hiroshima }\end{array}$ & $\begin{array}{l}\text { Mau Mau revolt, Russia launched } \\
\text { Sputnik, contraceptive pill, Nelson } \\
\text { Mandela sentenced to life, cold } \\
\text { war, assassinations, feminist } \\
\text { movement, Soweto riots }\end{array}$ & $\begin{array}{l}\text { Launched microchip, Watergate, } \\
\text { right to abortion, test-tube baby, } \\
\text { Margaret Thatcher - first female } \\
\text { Prime Minister, Working moms, } \\
\text { Challenger, latchkey kids, Berlin } \\
\text { wall comes down, divorced } \\
\text { parents, AIDS }\end{array}$ & $\begin{array}{l}\text { Internet, virtual communities, } \\
24 / 7 \text { lifestyle, baggage free, Nelson } \\
\text { Mandela released, Princess Diana } \\
\text { dies, Dolly the clone sheep, Viagra, } \\
\text { SMS, 9/11, Iraq war, email } \\
\text { spam increases }\end{array}$ \\
\hline Outlook & Victorian & Optimistic & Sceptical & Opportunity \\
\hline Work ethic & $\begin{array}{l}\text { Work hard because it is my duty, } \\
\text { life-time career }\end{array}$ & $\begin{array}{l}\text { Driven, self-fulfilling, makes me feel } \\
\text { important, job security and career }\end{array}$ & $\begin{array}{l}\text { Balanced, fund lifestyle, career } \\
\text { rather than security }\end{array}$ & $\begin{array}{l}\text { Enjoy change, entrepreneurial, will } \\
\text { help to change the world, parallel } \\
\text { career }\end{array}$ \\
\hline Success is a result of & Hard work & Political savvy, networking skills & Holding two jobs & $\begin{array}{l}\text { High energy, fast-thinking, quick- } \\
\text { learning }\end{array}$ \\
\hline Money is for & Security, save for a rainy day & Enjoyment, owe the bank money & Survival, means to an end & $\begin{array}{l}\text { Immediate gratification and to save } \\
\text { the world }\end{array}$ \\
\hline Education is & $\begin{array}{l}\text { Lucky to have one - We'll do our } \\
\text { very best }\end{array}$ & A birth right & I'll listen, but I can teach myself & $\begin{array}{l}\text { There's more to school than } \\
\text { memorising }\end{array}$ \\
\hline Health & Grinned and bore the pain & Doctor must cure me immediately & Alternative therapy & Obsessed with keeping healthy \\
\hline Feedback & No news is good news & Regular feedback & Immediate feedback & Feedback whenever I need \\
\hline
\end{tabular}

$\mathrm{PC}$, personal computer. 
uses the model by Bussin (2002a) as it is holistic and appropriate to South Africa.

Bussin (2002a) adapted a remuneration model called Total Reward Mix. The Reward Mix is structured in four categories namely pay, benefits, learning and development and the work environment. Figure 1 sets out the Total Reward Mix.

The pay component of the model includes a base salary, variable pay such as incentives, commissions and bonuses. Recognition could include dinners and award clubs, whilst shares or share options are linked to a long-term incentive.

The second aspect of this reward model is benefits. It consists of access to a medical aid, Employee Assistance Programmes (EAP), health care such as clinics and help lines. Retirement is often only considered in a serious light when employees are aging.

The world and the work environment change at a rapid pace. Employees want to learn and improve themselves. Companies that support learning and development are ranked high amongst the top companies to work for in South Africa (Corporate Research Foundation, 2005).

The work environment is not always considered as part of the reward strategy of a company. Technology and work relations are important aspects of the work environment. Wilson (1999) discussed the importance of the company culture, leadership, strategy and the impact thereof on the reward strategy. It is imperative for the company to provide performance support and constructive feedback to employees in order to adjust and grow, resulting in increased productivity and profitability (Milkovich \& Newman, 2005).

All companies have access to the four categories of rewards, but success lies in how these aspects are mixed and matched to address the employees' preferences. Milkovich and Newman (2005) developed a reward system model where the components are clearly stipulated as shown in Figure 2.

This model echoes the model that is used by Bussin (2002a). It is indicative of the fact that reward systems are multi-faceted and that no simple, single solution exists. From a practical viewpoint, the challenge is to manage the model in line with the requirements and expectations of the generations and to maintain a fair and equitable reward system, aligned to the company's strategic objectives.

Although reward models have broad strokes of similarity at a strategic level, an indicator of a successful reward system is the way in which it is deployed. For the purpose of this study, the Total Reward Mix model was used to facilitate the research as it was based on a South African context.

\section{Research on generations and rewards}

Very little research has been carried out on the relationship between generations and rewards. The research that has been performed has not found clear-cut results. For instance,
Giancola (2008) found that there is a greater importance of life stage over generation profiles in understanding employee needs. He also emphasised that all people are primarily concerned about their job, career and compensation, no matter what the generation and therefore concludes that reward preferences are determined by lifecycle rather than by generations.

Giancola (2006) has expressed his concern that the generation gap has been overstated by theorists and that the generation theory has major gaps. His research found that in terms of rewards, Baby Boomers are more interested in retirement planning and Generation Y prefers career development. He contends that these differences are linked to life stage rather than to generation preferences.

\section{Employee disposition}

Different people have different reward preferences based on their personal disposition. The research of Cable and Judge (1994) suggests that this has more to do with individual personality traits than with generation theory.

In a study conducted by Chiu, Luk and Tang (2002), it was suggested that reward preferences are more a function of economics, and are related to geography and culture. It was further contended that:

\begin{tabular}{|c|c|}
\hline Pay & Benefits \\
\hline - Base salary & - Health care \\
\hline - Variable pay & - Retirement \\
\hline - Recognition & - Savings \\
\hline \multirow[t]{2}{*}{ - Shares } & - Time off \\
\hline & - Perks \\
\hline Learning and Development & Work Environment \\
\hline - Career development & - Organisational climate \\
\hline - Performance management & - Leadership \\
\hline - Succession planning & - Performance support \\
\hline - Training & - Work and life balance \\
\hline
\end{tabular}

FIGURE 1: Total reward mix.

\begin{tabular}{|c|c|c|}
\hline \multicolumn{2}{|r|}{ Component of reward system } & \multirow{2}{*}{$\begin{array}{l}\text { Description } \\
\text { Salaries, wages, commissions and } \\
\text { bonuses }\end{array}$} \\
\hline 1. & Remuneration & \\
\hline 2. & Benefits & Vacations, health insurance \\
\hline 3. & Social interaction & Friendly workplace \\
\hline 4. & Security & Stable, consistent position and rewards \\
\hline 5. & Status or recognition & $\begin{array}{l}\text { Respect, prominence as a result of } \\
\text { work, opportunity to experience } \\
\text { different things }\end{array}$ \\
\hline 6. & Work variety & Right amount of work \\
\hline 7. & Workload & Is work valued by society \\
\hline 8. & Work importance & $\begin{array}{l}\text { Ability to influence others; control } \\
\text { own destiny, chance to be ahead }\end{array}$ \\
\hline 9. & Authority or control or autonomy & $\begin{array}{l}\text { Receive information helping to } \\
\text { improve performance, hazard free }\end{array}$ \\
\hline & Advancement & $\begin{array}{l}\text { Formal and informal training to learn } \\
\text { new knowledge, skills, abilities }\end{array}$ \\
\hline 11. & Feedback & - \\
\hline 12. & Work conditions & - \\
\hline 13. & Development opportunity & - \\
\hline
\end{tabular}

FIGURE 2: Components of total reward system. 
The meaning of money is 'in the eye of the beholder' and can be perceived as their 'frame of reference' in which they examine their everyday lives. On the one hand, it is possible to simply pay higher wages and lower benefits to satisfy employees' needs. On the other hand, some benefits are quite important to employees. The same benefit does not suit every worker. Workers do differ in their valuation of various benefits. Thus, a cafeteria plan, for example, which gives a worker more flexibility in benefit choices, can provide the most value to the worker for a given amount of expenditure. Researchers and managers of human resources and compensation need to identify the most important compensation components and satisfy employees' needs. (p. 403)

A framework of reward preferences and different generations has been established. The next sections set out the research design, results and discussion.

\section{Research design Research approach}

This research made use of a quantitative, cross-sectional, correlational design. A new questionnaire was developed and was forwarded via electronic mail to the Human Resources divisions of two ICT companies, based in Johannesburg. The contact people in the Human Resources divisions were asked to distribute the questionnaire to a stratified sample of staff. Thus primary data was used for the analysis.

\section{Research method}

\section{Research participants}

The staff complement for both companies combined is 4450 . The strata were proportionate by job level with every third person receiving a questionnaire. A total of 165 responses were received from the participants. This represents a response rate of $11 \%$. The respondents representing the various companies in the survey are reflected in Table 3.

The level of the participants' current positions is captured in Table 5. The participants were mainly general staff and supervisors, White and male. Generation $X$ and Baby Boomers were the two largest groups.

The valid percentage calculated took the dropout rate into account (Gourard, 2004). After cleaning the data, there were 164 usable responses.

\section{Measuring instruments}

A structured questionnaire was designed to gather the data on the reward preferences of the participants. The questionnaire consisted of closed-ended and ranking questions to gather the information. A combination of questions was used. Firstly, a 5-point Likert Scale was used, ranging from strongly agree to strongly disagree and secondly to correlate the views, it was combined with ranking questions.

Generations: The generations were categorised as follows:

- Veterans (1920-1940)

- Boomers (1941-1960)

- Generation X (1961-1980)

- Generation Y (1981-2000).
TABLE 3: Biographical details.

\begin{tabular}{|c|c|c|c|}
\hline Biographical detail & Descriptor & $\begin{array}{l}\text { Number of } \\
\text { participants }\end{array}$ & Percentage \\
\hline \multirow[t]{3}{*}{ Company } & Company A & 147 & 89.10 \\
\hline & Company B & 18 & 10.90 \\
\hline & Total & 165 & 100 \\
\hline \multirow[t]{6}{*}{ Level of position } & Top management & 12 & 7.30 \\
\hline & Senior management & 18 & 11.10 \\
\hline & Middle management & 35 & 21.30 \\
\hline & Supervisors & 46 & 28.00 \\
\hline & Staff & 53 & 32.30 \\
\hline & Total & 164 & 100 \\
\hline \multirow[t]{5}{*}{ Generations } & Veterans & 21 & 12.80 \\
\hline & Baby Boomers & 53 & 32.20 \\
\hline & Generation X & 52 & 31.70 \\
\hline & Generation Y & 38 & 23.20 \\
\hline & Total & 164 & 100 \\
\hline \multirow[t]{5}{*}{ Race } & White & 129 & 78.70 \\
\hline & Black & 27 & 16.50 \\
\hline & Indian & 4 & 2.40 \\
\hline & Coloured & 4 & 2.40 \\
\hline & Total & 164 & 100 \\
\hline \multirow[t]{3}{*}{ Gender } & Male & 96 & 58.50 \\
\hline & Female & 68 & 41.50 \\
\hline & Total & 164 & 100 \\
\hline \multirow[t]{5}{*}{ Marital Status } & Single, never married & 40 & 24.40 \\
\hline & Co-habituating & 6 & 3.70 \\
\hline & Married & 88 & 53.60 \\
\hline & $\begin{array}{l}\text { Separated, divorced, } \\
\text { widowed }\end{array}$ & 30 & 18.30 \\
\hline & Total & 164 & 100 \\
\hline
\end{tabular}

The limitation of this theoretical categorisation is acknowledged. It is, however, based on current literature, and needs to be validated in the South African context.

Reward: The questionnaire was divided into four categories of rewards.

Pay:

- base salary

- variable pay (commissions, incentives, bonuses, profit share, overtime, special assignment pay, standby allowance)

- recognition (status, prominence as a result of work status, work valued in society, awards, letters, complements, trophies, personalised items, hobbies)

- long-term incentives (deferred pay, shares schemes).

Benefits:

- health (medical aid, life insurance, on-site health care, HIV and/or Aids awareness and training, EAP, wellness programme, 24 hour hotline)

- retirement (provident fund, financial advice)

- savings (company contributions to provident fund)

- time-off (leave such as annual, sick, maternity or paternity, compassionate, family responsibility, community and charity, in lieu of overtime)

- perks (uniform allowance, travel, company arrangements with financial institutes, concierge services, crèches, canteens, security, petrol cards, cell phone allowances). 
Learning and development:

- career development (experience different things, challenges, promotion)

- performance management (feedback, right amount and complexity of work)

- succession plan (change to get ahead)

- training (knowledge, skills improvement, projects, experiential learning, formal development plans).

\section{Work environment:}

- organisational climate (friendly, secure, flexi-time, flexiplace, part-time, fun, peer and management relations, technology, 24/7 lifestyle, email, internet, shopping, global community, travel)

- leadership (ability to influence and inspire, values, participation)

- performance support (create a learning environment to support and enhance performance)

- work or life balance (work, personal, family, friends, hobbies and community).

Once completed, the Human Resources departments forwarded the electronic submissions to the researcher. The completed questionnaires were then forwarded to the Statistical Consultation Service at the University of Johannesburg for data capture and analysis.

\section{Research procedure}

The questionnaire was developed from the literature review and then piloted with 12 work colleagues and remuneration experts. Appropriate suggestions were taken into account and the questionnaire was amended accordingly. Human Resources representatives from two organisations were approached and asked if they would distribute the electronic questionnaire to a stratified sample of 1500 employees in their organisations. The questionnaire was then emailed to the selected employees, with a return date and address of the Human Resources representative. The completed questionnaires could be delivered anonymously, faxed or emailed to the Human Resources representative, who collated the responses for the researcher. Once the cut-off date had passed, the researcher collected the completed questionnaires from the Human Resources representatives.

\section{Statistical analysis}

In the research, the relationship between the Independent Variable (Generations) and the Dependent Variable (Rewards) was clarified. To determine the reward preferences of the generations, the Kruskal-Wallis Test was applied to determine the mean descriptives of each category related to the different generations.

\section{Results}

The specific aspects explored in this study were to determine if generations prefer different rewards or not. A synopsis of the biographical data is reflected in Table 3 in the previous section.
The item inter-correlation was subjected to a $\mathrm{KMO}$ and a Bartlett's test and was 0.761, which is higher than 0.7, making the matrix suitable for being factor analysed. Two factor analytic methods were used to determine the four factors, which are used in the research. Firstly, the extraction method was the Principal Axis Factoring and secondly, Varimax with Kaizer Normalisation was used as a rotation method. It was determined that the Cronbach alpha was 0.821 and therefore the scale was reliable. Table 4 reflects the outcome of the responses on a 5-point scale, which has been reduced to a 3-point scale for ease of reference. The categories of 'Not important at all' and 'Unimportant' were combined and were named 'Unimportant' in Table 6. The 'Important' category is a combination of 'Important' and 'Extremely important' categories.

During the analysis, five Eigen values (5.239; 2.148; 1.520 ; 1.333 and 1.055) were identified, which accounted for $66.4 \%$ of the variance. To compare the empirical research with the theory, a four factor analysis was forced. The outcome is reflected in Table 5. The communalities of the variables are determined for the first number of factors. This procedure is repeated until the sum does not change (Gorsuch, 1983). The Rotated Factor Matrix is displayed in Table 5, which displays the different item loadings on the four postulated factors.

The categories as per the literature research, versus the outcome of the empirical research, are reflected in Table 6. The literature research has four categories, namely pay, benefits, learning and development and work environment. During the empirical research, the sub-elements did not correlate completely to the literature research. The four categories in the empirical research were labelled Total Cost to Company (TCTC), over and above TCTC, career and work atmosphere.

Although the two clusters of categories are different, the outcome of the research still provides natural groupings of different categories or rewards, specific to the ICT industry. To determine the reward preferences of the generations the mean descriptive for each category is ranked per generations in Table 7.

In this section, statistical analyses were completed on the data to determine whether a relationship exists between the theory and the findings of the research. The Kruskal Wallis Test was used to test normality. None of the four categories was normally distributed. The Kruskal-Wallis Test identified a significant difference between Generation $X$ and Baby Boomers with their views around the category of career, $\mathrm{H}(2, N=93)=11.816, p<0.008$. No significant differences were found based on TCTC package, over and above package or the company's working atmosphere amongst the generations.

The Mann-Whitney $U$-test revealed that Generation $X$ $(n=43)$ will focus more on career than Baby Boomers $(n=50)$, $z=-3.364, p=0.05 / 6=0.0083$. From the summary in Table 7 , it is clear from the research that the generations prefer TCTC to the over and above TCTC rewards. 


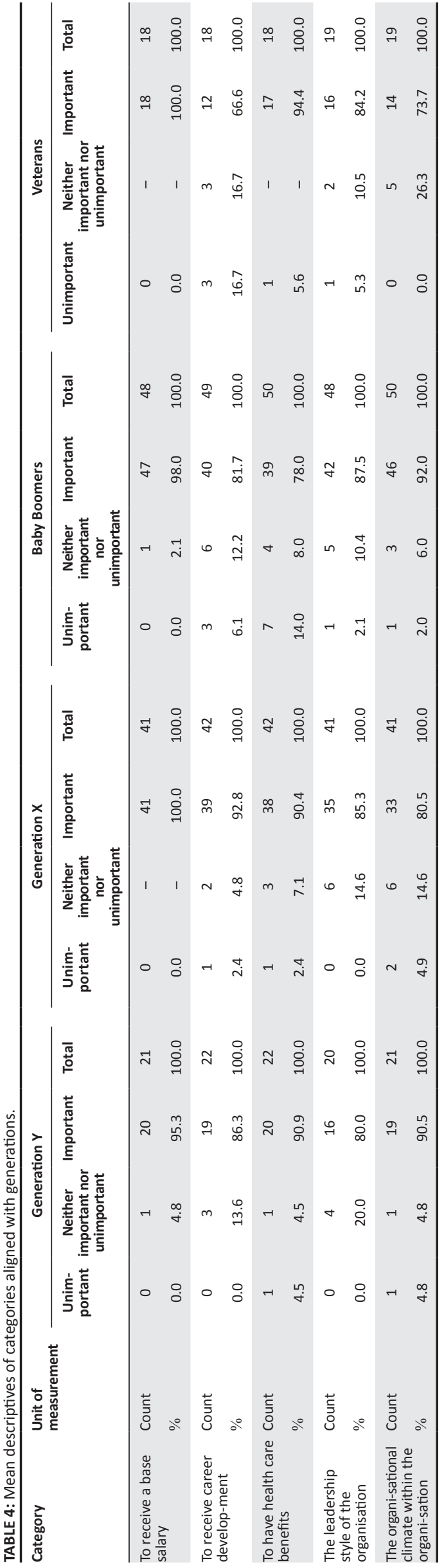

\section{Ethical considerations Potential benefits and hazards}

This research study posed no material hazard to any of the respondents. Although participants may benefit from an enriched theoretical understanding of the relationship between generations and reward strategies, there were no direct benefits associated with participation in the study.

\section{Recruitment procedures}

The stratified sample was randomly selected and no participants were singled-out or pre-selected. Participation was voluntary and there was no obligation to complete the questionnaires.

\section{Data protection}

All questionnaires were anonymous and no information can be linked back to individual participants. The confidentiality of the data was maintained throughout the study.

\section{Trustworthiness Reliability}

The internal reliability of the questionnaire was measured and a Cronbach's alpha of 0.821 indicates that the research instrument was reliable.

\section{Validity}

The reward labels assigned to the factor analysis are substantially similar to the reward models currently in use by the market today. This allowed some stability in the reward model relative to the literature and allowed the present research to focus on generation preferences.

\section{Discussion Outline of the results}

The findings of the research indicate that there is no direct relationship between reward preferences and generations in the ICT industry. This finding supports the research of Giancola (2008), who states that different generations do not prefer different rewards. All the generations rated TCTC (salary, health care, retirement benefits and share options) as the most important aspect of rewards, except for the Baby Boomers, who rated it in the second position. This finding supports work carried out by Medcof and Rumpel (2007) who found that pay and then benefits were preferred rewards.

The lowest rated aspect of rewards for all the generations that participated was over and above TCTC (perks, savings and variable pay). It is clear from the research that the older the participant, the lower the rating of the career (career development, performance management, performance support, recognition, succession planning, time off, training) aspect of rewards. Both Generations X and Y ranked career as second on their list of reward importance, whereas it slipped into third position for the Baby Boomers and in last position for the Veterans. 
TABLE 5: Results of the rotated factor matrix

\begin{tabular}{|c|c|c|c|c|}
\hline \multirow[t]{2}{*}{ Factor } & \multicolumn{4}{|c|}{ Rotated factor matrix } \\
\hline & 1 & 2 & 3 & 4 \\
\hline To have training opportunities & .854 & .087 & .050 & .071 \\
\hline To receive career development & .766 & .227 & .013 & -.071 \\
\hline To receive performance support in the organisation & .605 & .256 & .375 & .235 \\
\hline The performance management system in the organisation & .506 & .046 & .474 & .151 \\
\hline To have succession planning within the organisation & .483 & .458 & .184 & .015 \\
\hline To receive recognition within the organisation & .481 & .341 & .050 & .271 \\
\hline The have time-off options & .340 & .021 & .171 & .151 \\
\hline To receive share or share options & .040 & .617 & .158 & .025 \\
\hline To have health care benefits & .165 & .596 & .074 & .152 \\
\hline To receive retirement benefits & .269 & .549 & .003 & .411 \\
\hline To receive a base salary & .081 & .435 & .055 & .067 \\
\hline The organisational climate within the organisation & .136 & -.020 & .846 & -.007 \\
\hline The leadership style of the organisation & .156 & .207 & .740 & -.195 \\
\hline To receive incentives to save & .208 & .431 & -.085 & .641 \\
\hline To receive perks & .340 & .323 & -.037 & .614 \\
\hline To have a variable pay component as part of the remuneration plan & -.025 & -.008 & .104 & .572 \\
\hline
\end{tabular}

Extraction Method: Principal Axis Factoring.

Rotation Method: Varimax with Kaiser Normalisation.

Bold values indicate factor loadings.

TABLE 6: Categories according to the literature versus research.

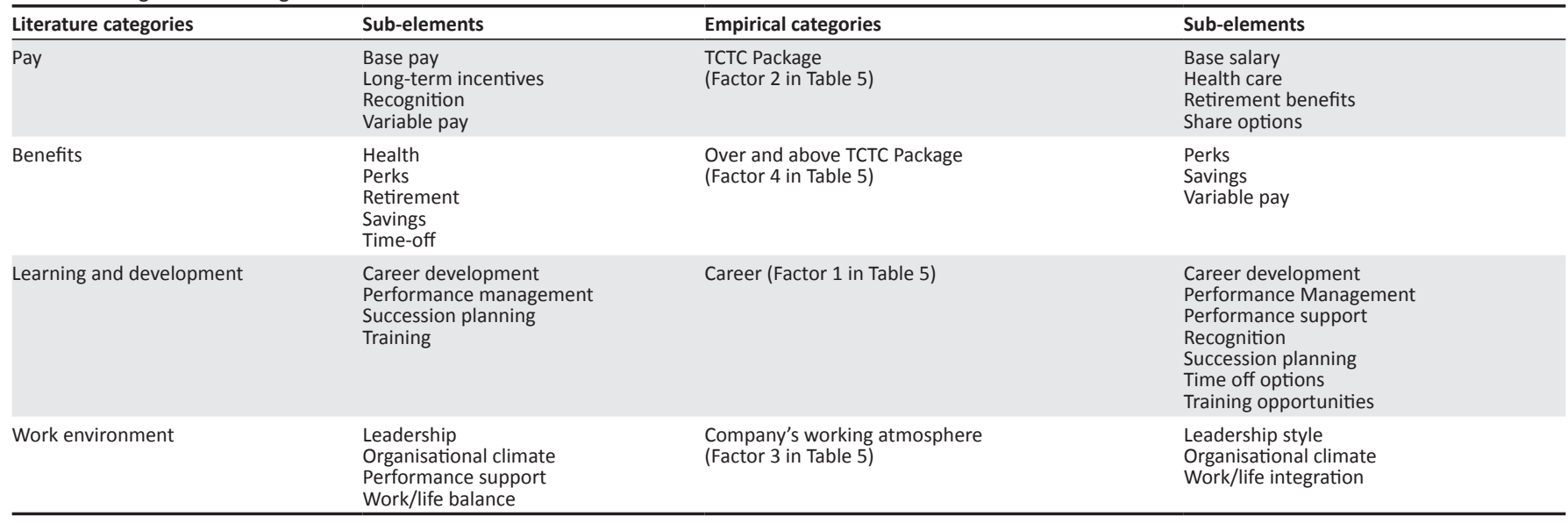

TCTC, Total Cost to Company.

TABLE 7: Mean descriptive of categories aligned with generations.

\begin{tabular}{|c|c|c|c|c|}
\hline Research categories & Generation Y (1981-2000) & Generation X (1961-1980) & Baby boomers (1941-1960) & Veterans (1921-1940) \\
\hline TCTC package & 4.42 & 4.59 & 4.32 & 4.54 \\
\hline Over and above TCTC package & 4.21 & 4.23 & 3.80 & 4.06 \\
\hline Career & 4.33 & 4.52 & 4.12 & 4.06 \\
\hline Company's working atmosphere & 4.33 & 4.44 & 4.50 & 4.39 \\
\hline
\end{tabular}

TCTC, Total Cost to Company.

The career aspect of reward is the only category that shows a significant difference (of 0.008 Kruskal-Wallis Non Para Metric, and 0.0083 as per the Mann-Whitney $U$-test, which are both smaller than 0.05 ). This significant difference may be subscribed to the lifecycle element as discussed by Giancola (2008). The rating of company atmosphere (leadership style, organisational climate and work and life integration) seems to vary amongst the generations. Interestingly, the Baby Boomers ranked the company's working atmosphere higher than TCTC.

It seems that the only way to determine staff members' aspirations is to talk to the individuals on a regular basis and to build solid and credible relationships. This is supported by research by Towers Perrin (2007), which resulted in the label 'my-pay-my-way'. This concept refers to employers asking employees specifically what their reward preferences are. This needs to be carried out within certain parameters and the benefit should outweigh the cost.

\section{Limitations of this research}

The following aspects are considered limitations to this study:

- Only two ICT companies participated in the survey, which may not be representative of the industry as a result of the core business focuses. 
- Surveys were self-administered, and relied on a volunteer sample.

- The research design was cross-sectional, and is not able to follow participants over time.

- The generation categories used come from global events and may not be $100 \%$ applicable to South Africa.

\section{Future research}

As a result of this study, the following research is suggested in this field:

- This study could be completed in a different industry to determine whether generations in different industries prefer different rewards.

- It is recommended that research is completed focusing on gender and race, to develop an even better reward model in the South African context.

- To measure the impact of a generation's customised reward strategy on staff retention and customer satisfaction, as well as the impact on the bottom line.

- To determine whether rewards are linked to the individual's career life cycle.

- To determine the reason(s) why Baby Boomers ranked Company's Work Atmosphere as the most important aspect of rewards.

\section{Recommendations and implications}

The findings have resolved the speculation that different generations prefer different rewards. Organisations have spent many hours researching and debating whether or not to tailor make their reward preferences by generation. The main recommendation is that organisations need not spend those hours or money in debate, but rather take the unit of analysis one level down to the individual employee.

The implication for management is that generation theory does not have a bearing on reward preferences, at least not in the ICT industry. Dissecting and tailor-making the reward strategy should not necessarily be performed according to generation theory, but should rather to be in touch with individual preferences. The trade-off from an organisation's point of view is whether the administrative burden associated with this flexibility is worth it. The implication for organisations is that they need to do their own cost-benefit analysis to determine how much reward flexibility they need to offer.

\section{Conclusion}

Rewards for generations in the ICT industry is a relatively new concept. This is the first known empirical study of its kind in South Africa. The primary purpose of this study was to determine whether reward preferences exist by generation in the ICT industry. The research was completed through a quantitative, structured survey by means of an electronic survey in two ICT companies. One hundred and sixty four valid responses were received. The trends reflected in this research mirror the research in the USA, where it is claimed that reward preferences are linked to lifecycle rather than generations.
The final conclusion is that although rewards are not linked to generations in the ICT industry, it is clear that one size does not fit all and companies need to be sensitive and provide employees with flexible rewards options.

\section{Acknowledgements Competing interests}

The authors declare that they have no financial or personal relationship(s) that may have inappropriately influenced them in writing this paper.

\section{Authors' contributions}

A.M. (University of Johannesburg) conceptualised the research topic, and conducted all field work and data analysis. M.B. (University of Johannesburg) supervised the conceptualisation, research, and analysis of this study and wrote the article for publication.

\section{References}

Bussin, M. (2002a). Choosing the right Incentive Scheme. Randburg: Knowledge Resources Publishing.

Bussin, M. (2002b). Retention Strategies. Randburg: Knowledge Resources Publishing. Bussin, M. (2003). Factors driving changes to remuneration policy and outcomes. Doctoral thesis, University of Johannesburg, Johannesburg, South Africa.

Cable, D.M., \& Judge, T.A. (1994). Pay preferences and job search decisions: A personorganization fir perspective. Personnel Psychology, 47, 317-348. http://dx.doi. org/10.1111/j.1744-6570.1994.tb01727.x

Chiang, F.F.T., \& Birtch, T.A. (2005). A taxonomy of reward preference: Examining country differences. Journal of International Management, 11, 357-375. http:// dx.doi.org/10.1016/j.intman.2005.06.004

Chiu, R.K., Luk, V.W., \& Tang, T.L. (2002). Retaining and motivating employees. Personal Review, 31(4), 404-431.

Corporate Leadership Council. (2002). The Compelling Offer Revisited: Changes in Employee Preferences over time. Washington DC: Corporate Executive Board.

Codrington, G., \& Grant-Marshall, S. (2004). Mind the Gap! Johannesburg: Penguin Books (Pty) Ltd.

Corporate Research Foundation. (2005). The Best Companies to work for in South Africa. (6th edn.). Paarl: Corporate Research Foundation Publishing.

Ellis, M. (2009). Win the race for talent. Retrieved May 29, 2009, from http://www. sbnonline.com/Classes

Giancola, F. (2006). The Generation Gap: More myth than Reality. HR. Human Resource Planning, 29(4), 32-37.

Giancola, F. (2008). Should generation profiles influence rewards strategy? Employee Relations Law Journal, 34(1), 56-68.

Gourard, S. (2004). Quantitative Methods in Social Science. Norfolk: Biddles Ltd.

Gorsuch, R. (1983). Factor Analysis. New Jersey: Lawrence Erlebaum Associates.

Karp, H., Fuller, C., \& Sirias, D. (2002). Bridging the Boomer Xer Gap Creating Authentic Teams for High Performance Work. California: Davis-Black Publishing.

Lammiman, J., \& Syrett, M. (2004). Cool Search. Cornwall: TJ International Ltd.

MacGrain Herkenhoff, L.M. (2000). Motivational remuneration (pay) preferences: Cultural analysis within the Hofstede model. USA: Dissertation.com.

MacGrain Herkenhoff, L.M. (2002). National Remuneration (Pay) Preferences: Cultural Analysis within the Hofstede Model Using Cultural Values to Untangle the Web of Global Pay. University of Western Australia, Perth: Universal Publishers.

Medcof, J.W., \& Rumpel, S. (2007). High technology workers and total rewards. Journal of High Technology Management Research, 18, 59-72. http://dx.doi. org/10.1016/j.hitech.2007.03.004

Milkovich, G.T., \& Newman, M.N. (2005). Compensation. (8th edn.). United States: Irwin/McGraw-Hill.

Mohlala, J.G. (2011). Employee retention within Standard Bank Group IT. MBA thesis, University of Johannesburg, Johannesburg, South Africa.

P-E Corporate Services SA (Pty) Ltd. (2010). Human resources practitioner's handbook. Johannesburg: P-E Corporate Services.

Nienaber, N., \& Bussin, M. (2009). The relationship between personality types and reward preferences. Doctoral thesis, University of Johannesburg, Johannesburg, South Africa.

Shelton, C., \& Shelton, L. (2005). The NeXt revolution. California: Davis-Black Publishing.

Towers Perrin. (2007). Using total rewards to build an effective employee value proposition. Retrieved May 15, 2008, from http://www.towersperrin.com

Van Rooy, D. (2010). Total rewards strategy for a multi-generational workforce. Unpublished MBA thesis, Gordan Institute of Business Science, Johannesburg, South Africa.

Wilson, T. (1999). Rewards that drive high performance. New York: AMACOM. 